Supporting Information

\title{
Integration of Janus Wettability and Heat Conduction in Hierarchically Designed Textiles for All-Day Personal Radiative Cooling
}

Dongyang Miao, ${ }^{\dagger}$ Ningbo Cheng, ${ }^{\dagger}$ Xianfeng Wang, ${ }^{*, \dagger}$ Jianyong $Y u,{ }^{*, \dagger}$ and Bin Ding ${ }^{*, \dagger}$

$\dagger$ Innovation Center for Textile Science and Technology, College of Textiles, Donghua University, Shanghai 201620, China.

†College of Fashion and Design, Donghua University, Shanghai 200051, China.

*Xianfeng Wang Email: wxf@ dhu.edu.cn.

*Jianyong Yu Email: yujy@ dhu.edu.cn.

*Bin Ding Email: binding@dhu.edu.cn. 


\section{Materials and Methods}

\section{$\underline{\text { Fabrication of } \mathrm{PU} / \mathrm{Si}_{3} \mathrm{~N}_{4}-\mathrm{CM}}$}

$\mathrm{Si}_{3} \mathrm{~N}_{4}$ microparticles (diameter of $1.96 \mu \mathrm{m}$, Desunmet Special Ceramics Co., Ltd.), zirconia beads, and distilled water were added to a $100 \mathrm{~mL}$ ball milling jar with a mass ratio of 10:2:1.8. $\mathrm{Si}_{3} \mathrm{~N}_{4}$ particles with diameters of $0.96,0.71$, and $0.45 \mu \mathrm{m}$ were obtained by running the ball milling

process for 1,2 , and $4 \mathrm{~h}$, respectively. To prepare $\mathrm{PU} / \mathrm{Si}_{3} \mathrm{~N}_{4}-\mathrm{CM}, \mathrm{Si}_{3} \mathrm{~N}_{4}$ particles were dispersed in dimethylformamide (DMF, Aladdin, 99.8\%). PU (A85P4394, Huntsman International LLC) was then dissolved in the DMF solution to obtain a $\mathrm{PU} / \mathrm{Si}_{3} \mathrm{~N}_{4} / \mathrm{DMF}$ precursor solution with a 7:3:90 mass ratio. Precursor solutions were drop-casted onto smooth substrates (i.e., petri dishes) to achieve the desired casting thickness $(200 \mu \mathrm{m})$. The freestanding solid membranes were peeled off from the substrates after vacuum drying at $70^{\circ} \mathrm{C}$ for $12 \mathrm{~h}$. PU/Si3 $\mathrm{N}_{4}-\mathrm{CM}$ membranes were prepared using $\mathrm{Si}_{3} \mathrm{~N}_{4}$ particles with diameters of $1.96,0.96,0.71$, and $0.45 \mu \mathrm{m}$. Additionally, a PU matrix without $\mathrm{Si}_{3} \mathrm{~N}_{4}$ particles was prepared using the same process.

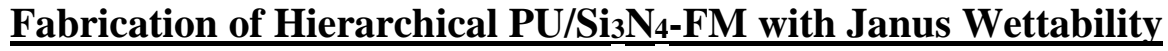

For the preparation of hierarchical PU/Si $3 \mathrm{~N}_{4}-\mathrm{FM}\left(\mathrm{Si}_{3} \mathrm{~N}_{4}\right.$ loading of $30 \mathrm{wt}$. \%, fiber diameter of 0.74 $\mu \mathrm{m}$ ), the $\mathrm{Si}_{3} \mathrm{~N}_{4}$ nanoparticles (diameter of $0.45 \mu \mathrm{m}$ ) were first dispersed in a mixed dual solvent of DMF and acetone (mass ratio of 4:6). PU was then dissolved in the mixed solvent to obtain a $\mathrm{PU} / \mathrm{Si}_{3} \mathrm{~N}_{4} / \mathrm{dual}$ solvent precursor solution with a 10.5:4.5:85 mass ratio. The precursor solution was electrospun with an applied voltage of $30 \mathrm{kV}$, a collection distance of $15 \mathrm{~cm}$, and a feed rate of 2 $\mathrm{mL} \mathrm{h}^{-1}$ under an ambient temperature of $25 \pm 2{ }^{\circ} \mathrm{C}$ and humidity of $80 \pm 2 \%$. When the fibrous membrane achieved the desired thickness $(200 \mu \mathrm{m})$, it was peeled off from the collector and vacuum dried at $70{ }^{\circ} \mathrm{C}$ for $2 \mathrm{~h}$. It should be noted that this electrospinning process can be scaled up in a roll-to-roll manner at a speed of $1 \mathrm{~m} \mathrm{~min}^{-1}$ with $200 \mu \mathrm{m}$ thickness. Additionally, 
$\mathrm{PU} / \mathrm{Si}_{3} \mathrm{~N}_{4} /$ dual solvent precursor solutions were also made with mass ratios of 14:6:80, 12:5.2:82.8, 9:3.9:87.1, and 8:3.4:88.6 for the preparation of $\mathrm{PU} / \mathrm{Si}_{3} \mathrm{~N}_{4}-\mathrm{FM}$ with thinner fibers. To obtain Janus wettability, the hierarchical PU/Si $3 \mathrm{~N}_{4}-\mathrm{FMs}$ were modified by single-side plasma treatment with a plasma reactor (PDC-32G-2, Harrick Plasma Inc.) under an air flow rate of $50 \mathrm{~mL} \mathrm{~min}{ }^{-1}$ and a radio frequency (RF) power of $18 \mathrm{~W}$ for $10 \mathrm{~min}$. Notably, when the fibrous membrane was treated by the plasma on one side, a superhydrophilic-to-hydrophobic gradient was created across the thickness of the membrane. The cotton textile used for comparison was commercially obtained (single jersey, $170 \mathrm{~g} \mathrm{~m}^{-2}, \sim 500 \mu \mathrm{m}$ thickness).

\section{Material Characterization}

SEM images and elemental maps were obtained using an SU 5000 microscope (Hitachi Ltd.) coupled with an energy dispersive spectrometry (EDS, XFlash 610M, Bruker Co.). The $\mathrm{Si}_{3} \mathrm{~N}_{4}$ particle diameter distribution was measured by a Zetasizer Nano ZS (Malvern Panalytical Ltd.) and the fiber diameters were measured based on the SEM image analysis software. The mechanical properties of the samples were measured by a dynamic mechanical analyzer instrument (Q850, TA Instruments Inc.). For this analysis, the $\mathrm{PU} / \mathrm{Si}_{3} \mathrm{~N}_{4}-\mathrm{FM}$ samples were cut into $5 \mathrm{~mm}$ wide strips and cyclic tension tests were performed with a tensile speed of $100 \% \mathrm{~min}^{-1}$ and a $50 \%$ strain. The water evaporation rate was measured according to the standard GB/T 21655.1. $0.2 \mathrm{~g}$ deionized water was applied to the center of samples $(10 \mathrm{~cm} \times 10 \mathrm{~cm})$ and mass loss was measured every 5 min. Thermal conductivity was calculated as shown in equation (1):

$$
K=\alpha \cdot \rho \cdot C_{\mathrm{p}}
$$

where $\alpha$ is thermal diffusivity, $\rho$ is the density of a sample, and $C_{\mathrm{p}}$ is specific heat capacity. Thermal diffusivity was directly determined by laser flash analysis (LFA 467, NETZSCH Co.) at room temperature. The samples were pre-coated with platinum by an ion sputter (MC1000, Hitachi 
Ltd.) to mitigate their translucent nature and to collect heat on their surfaces. Density was calculated by the measured weights and geometric volumes of the samples. Specific heat capacities were obtained with a differential scan calorimeter (DSC2500, TA Instruments Inc.) under a nitrogen atmosphere using sapphire as the standard material. An infrared camera (TiS75, Fluke Co.) was used to record the surface temperature of the fibrous membranes. Infrared absorbance spectra were obtained using an ATR-FTIR spectrometer (Nicolet iS10, Thermo Fisher Scientific Inc.). Pore size distribution was measured using a capillary flow porometer (CFP-1100AI, Porous Materials Inc.). WCAs were recorded by a drop contact angle meter (SL200KS, Kino Industry Ltd.). Water vapor transport (WVT) rate was tested according to the ASTM E96 upright cup standard. AFM analysis was performed with an AFM microscope (Bruker Co.) in tapping mode and surface roughness was calculated with the associated NanoScope Analysis software.

\section{$\underline{\text { Optical Characterization }}$}

Solar $(0.25$ to $2.5 \mu \mathrm{m})$ reflectance $(R)$ was measured by an ultraviolet-visible-near-infrared (UVVis-NIR) spectrophotometer (UV3600, Shimadzu Co.) coupled with a diffuse integrating sphere (ISR-3100, Shimadzu). A pristine, calibrated diffuse reflector (BB20050, National Institute of Metrology) was used as the reference. The IR $(2.5$ to $16.7 \mu \mathrm{m})$ reflectance $(R)$ and transmittance

(T) were obtained by the FTIR spectrometer (Nicolet iS50, Thermo Fisher Scientific Inc.) coupled with a diffuse gold-coated integrating sphere (Mid-IR IntegratIR, PIKE Technologies Inc.) and a mercury cadmium telluride detector. A gold-coated background plate was used as the reference. Angular measurements were taken with the samples placed inside the integrating sphere at different angles to intercept the incident light. Additional specular reflectance in the solar region was measured by a Lambda 1050 (PerkinElmer, Inc.) with a universal reflectance accessory (URA). Kirchhoff's law states that the radiation emitted by an object in thermal equilibrium must be equal 
to the radiation absorbed by the object. ${ }^{1}$ Therefore, the emittance $(\varepsilon)$ can be defined as shown in equation (2):

$$
\varepsilon=100-T-R
$$

The complex spectral refractive indexes of the solid PU matrix and $\mathrm{PU} / \mathrm{Si}_{3} \mathrm{~N}_{4}-\mathrm{CM}$ in the 0.25 to $16.7 \mu \mathrm{m}$ wavelength range were obtained using an RC2 ellipsometer and an IR-VASE Mark II ellipsometer (J. A. Woollam Co.).

\section{Demonstration of Antigravity Directional Water Transport}

A syringe needle was placed under the hierarchical PU/Si ${ }_{3} \mathrm{~N}_{4}-\mathrm{FM}$ and a $5 \mu \mathrm{L}$ water droplet labeled with sodium fluorescein $(0.1 \mathrm{wt} . \%)$ was attached to the lower surface of the membrane under UV radiation $(\lambda=365 \mathrm{~nm})$. Images were taken at $50 \mathrm{fps}$ to determine the water contact angle with a high-speed camera.

\section{Measurement of Outdoor Cooling Performance and Simulation of Sweat Evaporation}

Skin simulators were constructed by using silicone rubber heaters (diameter of $10 \mathrm{~cm}$, Omega Inc.) connected to a power supply (2280S-60-3, Keithley Inc.). The generated heating power density for each skin simulator was set as $100 \mathrm{~W} \mathrm{~m}^{-2}$ to mimic metabolic heat production. The skin simulators were sandwiched between textile samples and insulating foam. T-type thermocouples were connected to a temperature monitor to record the simulated skin temperature (JK808, Jinko Co., Ltd.). The setup was exposed to the outdoor environment to obtain real-time temperature tracking of ambient air, a bare skin simulator, a cotton-covered skin simulator, and a PU/Si3 $\mathrm{N}_{4}-\mathrm{FM}$-covered skin simulator. A pyranometer (TBQ-2L, Licheng Auto Equipment Ltd.) was placed next to the samples to record the total (direct and diffuse) solar irradiance. The all-day continuous cooling performance of PU/Si ${ }_{3} \mathrm{~N}_{4}-\mathrm{FM}$ and cotton was conducted at Donghua University, Shanghai, China 
between June 5, 2021 and June 7, 2021 (Eastern China, Coastal, 31 ${ }^{\circ} 06^{\prime} 30^{\prime \prime} \mathrm{N}, 121^{\circ} 21^{\prime} 74^{\prime \prime} \mathrm{E}$ ). The relative humidity was $\sim 50 \%$ and the wind speed was $\sim 2 \mathrm{~m} \mathrm{~s}^{-1}$ (light breeze).

To simulate the cooling effect caused by sweat evaporation, a syringe pump was used to provide a continuous water supply at flow rates of $0.25,0.5,1,2$, and $5 \mathrm{~mL} \mathrm{~h}^{-1}$ on the skin simulators (Figure S17). According to Figure $4 \mathrm{~b}$, the cotton-covered and $\mathrm{PU} / \mathrm{Si}_{3} \mathrm{~N}_{4}-\mathrm{FM}$-covered skin simulators exhibited respective average temperatures of $\sim 65.1{ }^{\circ} \mathrm{C}$ and $\sim 43.2^{\circ} \mathrm{C}$ under the sun at noon (12 p.m.) on June 5, 2021 to June 7, 2021. Thus, they were provided with heating power densities of 737 and $329 \mathrm{~W} \mathrm{~m}^{-2}$ to reach the same two temperatures. The real-time temperatures of the skin simulators under increasing water supply were recorded at a room temperature of $25 \pm$ $2{ }^{\circ} \mathrm{C}$ and humidity of $50 \pm 2 \%$.

\section{Definition of Average Solar Reflectance and Human Body Infrared (HBIR) Emittance}

The average solar reflectance $\left(\bar{R}_{\text {solar }}\right)$ is defined as shown in equation (1):

$$
\bar{R}_{\text {solar }}=\frac{\int_{0.3 \mu \mathrm{m}}^{2.5 \mu \mathrm{m}} I_{\text {solar }}(\lambda) \cdot R(\lambda) \mathrm{d} \lambda}{\int_{0.3 \mu \mathrm{m}}^{2.5 \mu \mathrm{m}} I_{\text {solar }}(\lambda) \mathrm{d} \lambda}
$$

where $\lambda$ is the solar wavelength, $I_{\text {solar }}(\lambda)$ is the normalized ASTM G173 global solar spectrum, ${ }^{2}$ and $R(\lambda)$ is the sample's spectral reflectance. ${ }^{3}$ Similarly, the average HBIR emittance $\left(\bar{\varepsilon}_{\mathrm{HBIR}}\right)$ is defined as shown in equation (2):

$$
\bar{\varepsilon}_{\mathrm{HBIR}}=\frac{\int_{2.5 \mu \mathrm{m}}^{16.7 \mu \mathrm{m}} I_{\mathrm{HB}}(\lambda) \cdot \varepsilon(\lambda) \mathrm{d} \lambda}{\int_{2.5 \mu \mathrm{m}}^{16.7 \mu \mathrm{m}} I_{\mathrm{HB}}(\lambda) \mathrm{d} \lambda}
$$

where $\varepsilon(\lambda)$ is the sample's spectral emittance and $I_{\mathrm{HB}}(\lambda)$ is the spectral emittance of the human body (assumed to be a standard black body, $34{ }^{\circ} \mathrm{C}$ ). The spectral emittance of a black body at temperature $T$ is calculated as shown in equation (3): 


$$
I_{\mathrm{HB}}(\lambda, T)=\frac{2 h c^{2}}{\lambda^{5}} \cdot \frac{1}{e^{h c /\left(\lambda \kappa_{\mathrm{B}} T\right)}-1}
$$

where $h$ is Planck's constant, $\kappa_{\mathrm{B}}$ is Boltzmann's constant, and $c$ is the speed of light. ${ }^{4}$

\section{$\underline{\text { Numerical Simulation }}$}

To theoretically investigate the influence of solid $\mathrm{PU} / \mathrm{Si}_{3} \mathrm{~N}_{4}-\mathrm{CM}$ and the fibrous structural feature on the scattering properties of $\mathrm{PU} / \mathrm{Si}_{3} \mathrm{~N}_{4}-\mathrm{FM}$, finite-difference time-domain (FDTD) simulations were used, as shown in Figure S5. ${ }^{5}$ The scattering efficiencies of both PU/Si3 $\mathrm{N}_{4}-\mathrm{CM}$ and $\mathrm{PU} / \mathrm{Si}_{3} \mathrm{~N}_{4}$ fibers were simulated across the entire solar region $(0.3$ to $2.5 \mu \mathrm{m})$. The complex spectral refractive indexes of the PU matrix and $\mathrm{PU} / \mathrm{Si}_{3} \mathrm{~N}_{4}-\mathrm{CM}$ were measured using an ellipsometer, as shown in Figure 2c. The complex refractive index of $\mathrm{Si}_{3} \mathrm{~N}_{4}$ was obtained from the literature. ${ }^{6}$ Perfect matching layer (PML) absorption boundary conditions and a total field scattering field (TFSF) source were used. For the scattering cross-sections of $\mathrm{PU} / \mathrm{Si}_{3} \mathrm{~N}_{4}-\mathrm{CM}$, a PU polymeric matrix embedded with scattering $\mathrm{Si}_{3} \mathrm{~N}_{4}$ particle with sizes ranging from 0.1 to $2.5 \mu \mathrm{m}$ was used (Figure S5a). For the scattering cross-sections of $\mathrm{PU} / \mathrm{Si}_{3} \mathrm{~N}_{4}-\mathrm{FM}$, a single $\mathrm{PU} / \mathrm{Si}_{3} \mathrm{~N}_{4}$ composite fiber with a diameter ranging from 0.1 to $1.8 \mu \mathrm{m}$ was used (Figure $\mathrm{S} 5 \mathrm{~b}$ ).

\section{Quantified Analysis of Directional Water Transport Capacity}

Directional water transport capacity was measured by a moisture management tester (M290, SDL Atlas, Ltd.) based on the standard AATCC TM-195. A textile sample was horizontally placed between the top and bottom sensors, and 0.9 wt.\% sodium chloride solution $(0.21 \mathrm{~g}$, representing perspiration) was dropped on the center of the sample. As the solution was transported across the sample, the corresponding electrical resistance on the top and bottom surface was recorded and the relative water content was quantitatively calculated. The directional water transport index $(\mathrm{R})$ is defined as the difference between the accumulated water content on the top and bottom surface of a sample, calculated as shown in equation (4): 


$$
\mathrm{R}=\frac{1}{T_{0}} \int\left[U_{\mathrm{b}}(T)-U_{\mathrm{t}}(T)\right] \mathrm{d} T
$$

where $T$ is the testing time and $U_{\mathrm{t}}$ and $U_{\mathrm{b}}$ are the real-time water content on the top and bottom surface of the sample.

\section{Supplementary Figures}

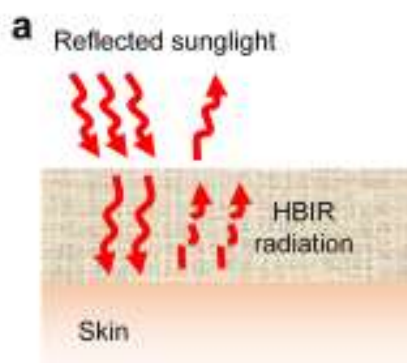

Traditional textile b Reflected sunglight
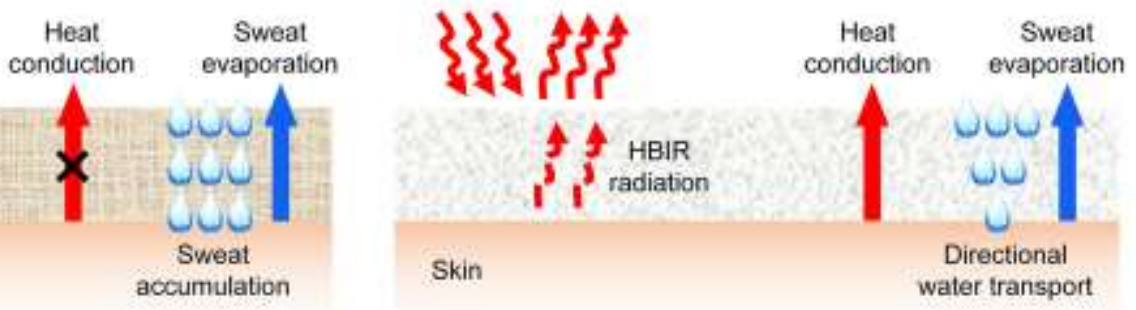

Hierarchical PU/Si $\mathrm{N}_{4}-\mathrm{FM}$

Figure S1. Heat dissipation process of traditional textile and hierarchical $\mathrm{PU} / \mathrm{Si}_{3} \mathrm{~N}_{4}-\mathrm{FM}$ with Janus wettability. (a) Traditional textiles only exhibit desired HBIR emittance. The limited solar reflectance, heat conduction and sweat evaporation cannot provided efficient cooling effect. (b) The hierarchical PU/Si ${ }_{3} \mathrm{~N}_{4}-\mathrm{FM}$ not only emitted the HBIR radiation but also reflected sunlight, showing the efficient radiative cooling. In addition, the plasma-treated $\mathrm{PU} / \mathrm{Si}_{3} \mathrm{~N}_{4}-\mathrm{FM}$ provides interconnected heat transfer and directional water transport pathways for the sweat evaporative cooling. 

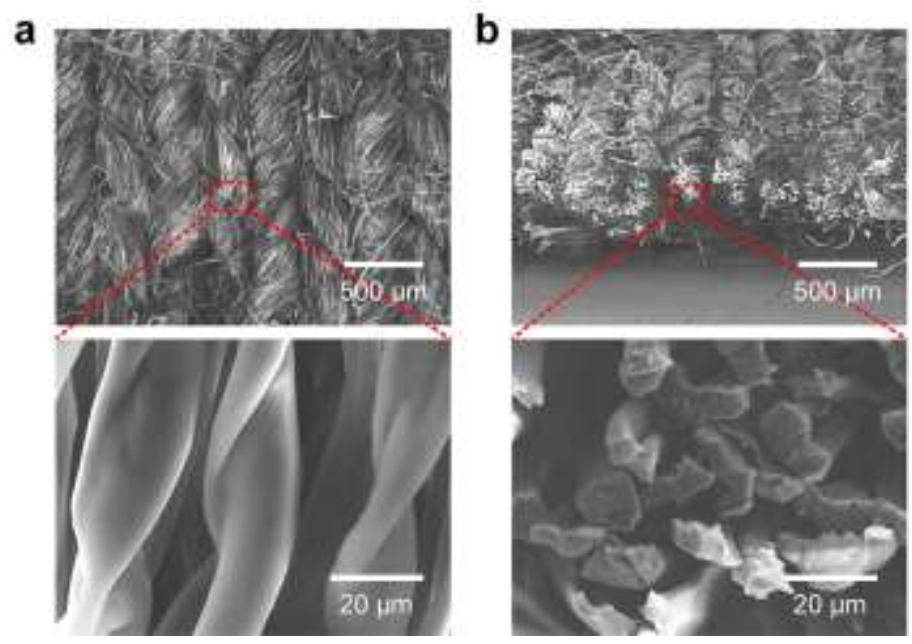

Figure S2. Typical morphology of cotton textile. (a) SEM top view of the cotton textile and magnified view of the center. (b) SEM cross-sectional view of the cotton textile and magnified view of the center.

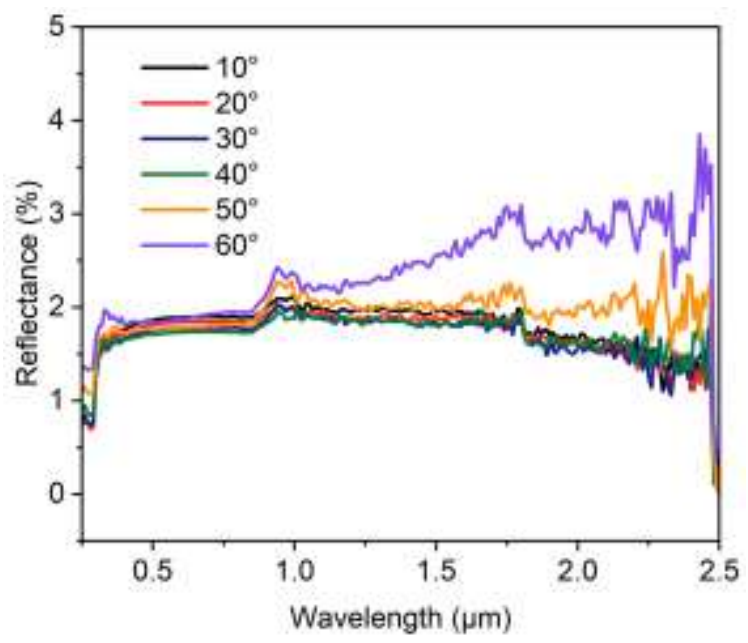

Figure S3. Specular reflectance of the $\mathrm{PU} / \mathrm{Si}_{3} \mathrm{~N}_{4}-\mathrm{FM}$ at different incident angles. The $\mathrm{PU} / \mathrm{Si}_{3} \mathrm{~N}_{4}-\mathrm{FM}$ displayed limited specular reflectance which is related to the diffused reflectance response. 


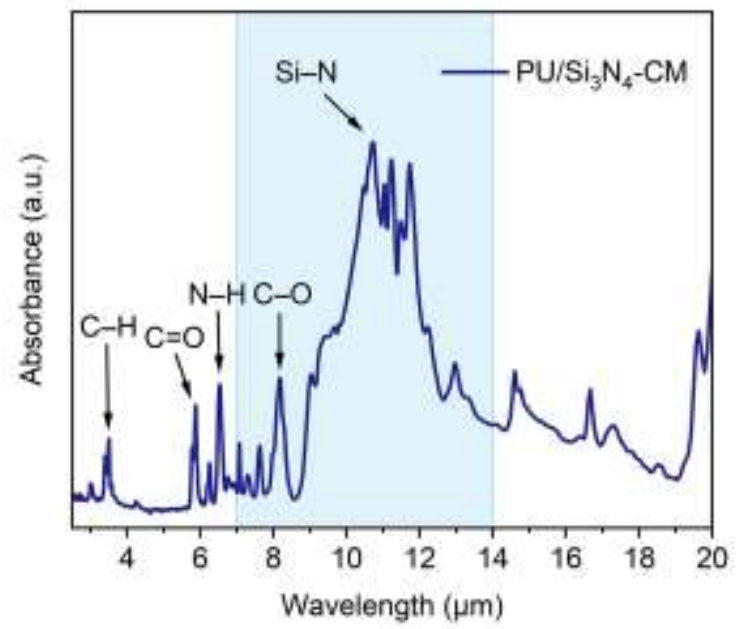

Figure S4. Absorbance spectrum of PU/Si3 N4-CM measured with ATR-FTIR spectroscopy.
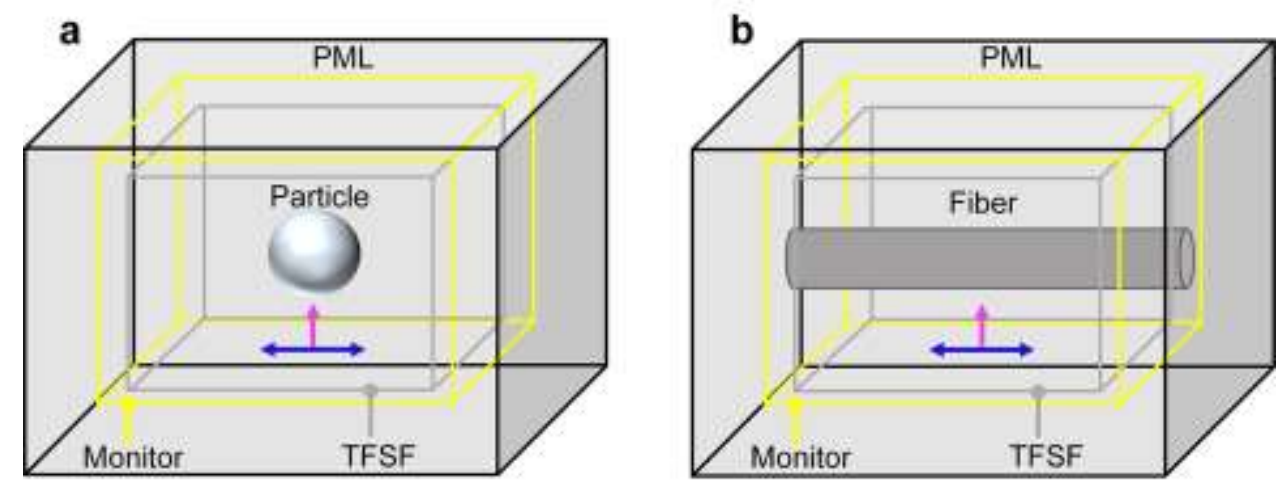

Figure S5. Schematic showing the Finite-Difference Time-Domain (FDTD) simulation setups. (a) Scattering medium of PU/Si $3 \mathrm{~N}_{4}-\mathrm{CM}$. (b) Scattering medium of a $\mathrm{PU} / \mathrm{Si}_{3} \mathrm{~N}_{4}$ fibers. 

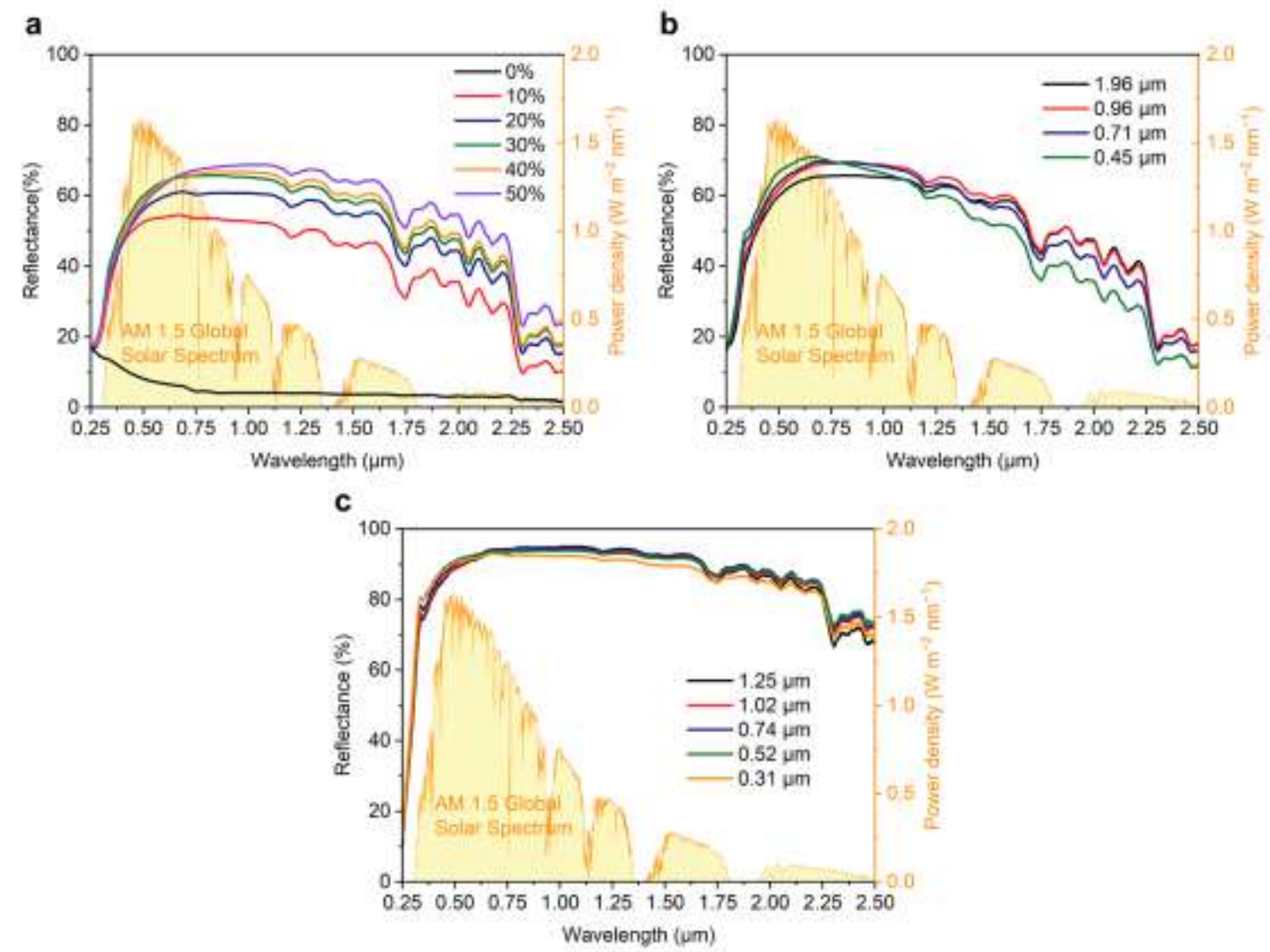

Figure S6. Influence of nanoparticle loading, nanoparticle diameter and fiber diameter on the optical performance. (a) UV-vis-NIR reflectance measurement of the $\mathrm{PU} / \mathrm{Si}_{3} \mathrm{~N}_{4}-\mathrm{CM}$ as a function of $\mathrm{Si}_{3} \mathrm{~N}_{4}$ particle loading with fixed diameter $(1.96 \mu \mathrm{m})$. (b) UV-vis-NIR reflectance of the PU/Si $\mathrm{N}_{4}-\mathrm{CM}$ as a function of particle diameter with fixed loading (30 wt.\%). (c) UV-vis-NIR reflectance of the PU/Si $\mathrm{N}_{4}-\mathrm{FM}$ as a function of fiber diameter with fixed particle diameter (1.96 $\mu \mathrm{m})$ and loading (30 wt.\%). Yellow shaded area is the AM 1.5 global solar spectrum. 
a

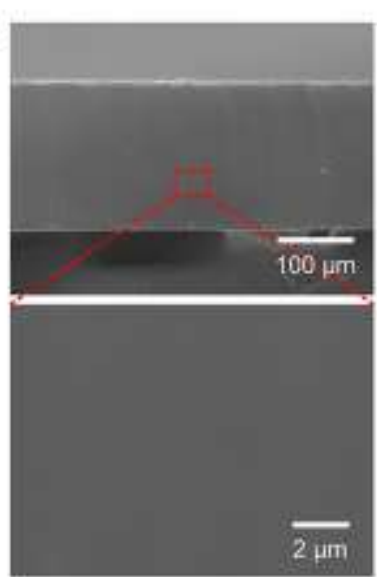

d
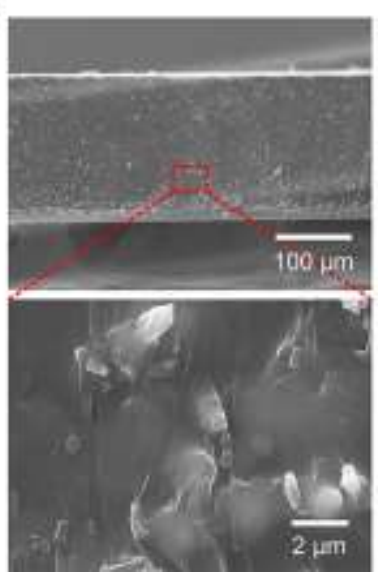

b
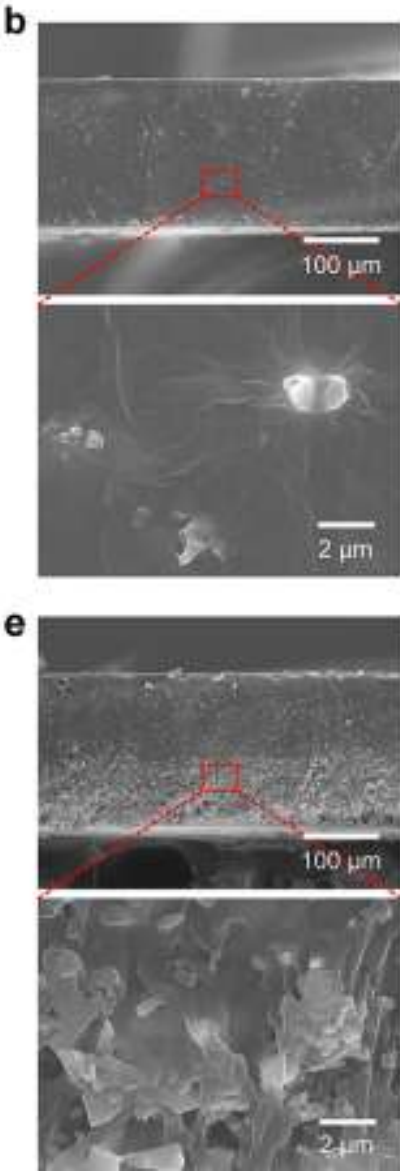
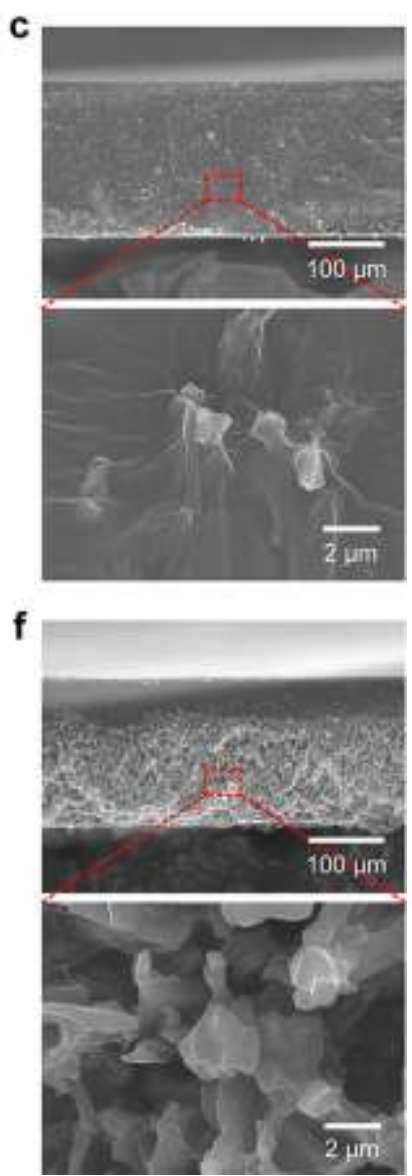

Figure S7. Typical morphology of $\mathrm{PU} / \mathrm{Si}_{3} \mathrm{~N}_{4}-\mathrm{CM}$ with increasing $\mathrm{Si}_{3} \mathrm{~N}_{4}$ loading. (a-f) SEM cross-sectional view image of the $\mathrm{PU} / \mathrm{Si}_{3} \mathrm{~N}_{4}-\mathrm{CM}$ and magnified view of the center. The $\mathrm{Si}_{3} \mathrm{~N}_{4}$ particles with diameter of $1.96 \mu \mathrm{m}$ were randomly embedded in the PU matrix at $\mathrm{Si}_{3} \mathrm{~N}_{4}$ loadings of $0,10,20,30,40$, and $50 \mathrm{wt} \%$. The magnified view shows undesirable porous structures were formed on part of the cross-section when the $\mathrm{Si}_{3} \mathrm{~N}_{4}$ loading is greater than $40 \mathrm{wt} . \%$. 


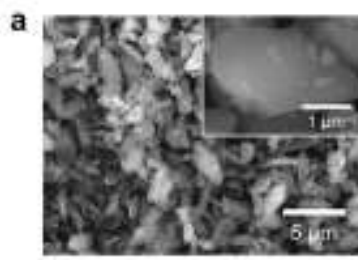

e

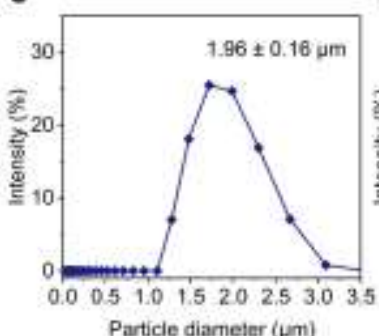

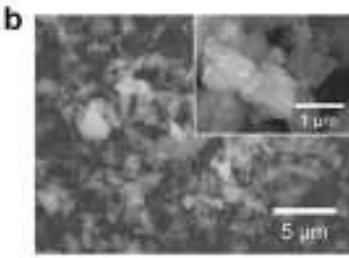

f

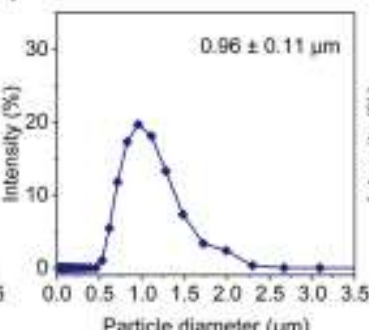

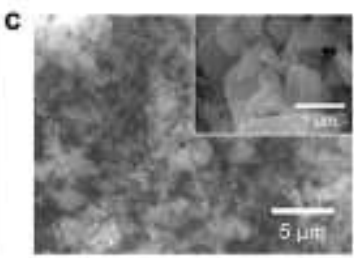

g

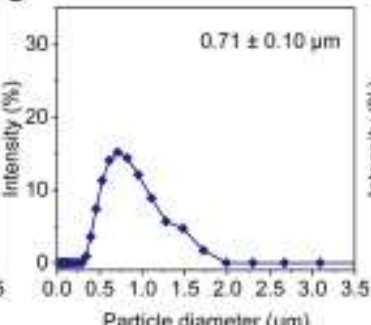

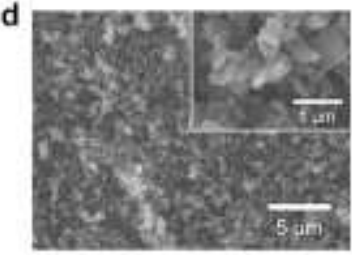

h

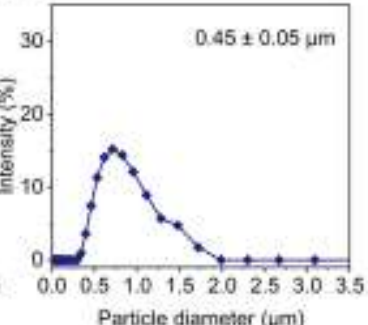

Figure S8. Typical morphology of the $\mathrm{Si}_{3} \mathrm{~N}_{4}$ particles. (a-d) SEM images of the $\mathrm{Si}_{3} \mathrm{~N}_{4}$ particles with decreasing diameter of $1.96,0.96,0.71$ and $0.45 \mu \mathrm{m}$. (e-h) The corresponding particle diameter distributions of the $\mathrm{Si}_{3} \mathrm{~N}_{4}$ particles with decreasing diameter of $1.96,0.96,0.71$ and 0.45 $\mu \mathrm{m}$. The $\mathrm{Si}_{3} \mathrm{~N}_{4}$ particles with decreasing diameter of $1.96,0.96,0.71$ and $0.45 \mu \mathrm{m}$ were obtained by running the ball milling process for $0,1,2$ and $4 \mathrm{~h}$, respectively.
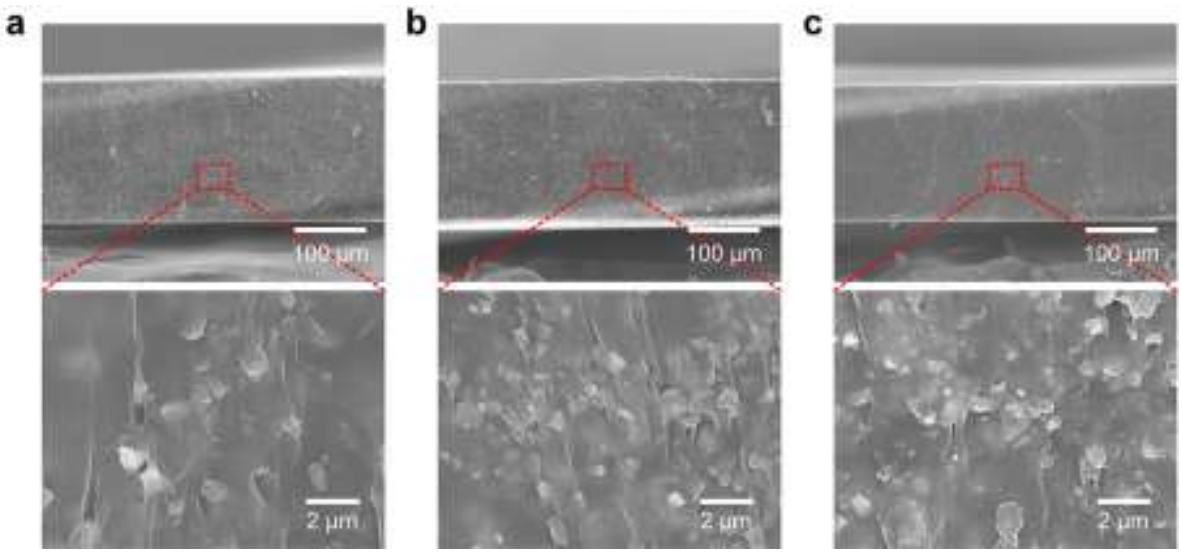

Figure S9. Typical morphology of $\mathrm{PU} / \mathrm{Si}_{3} \mathrm{~N}_{4}-\mathrm{CM}$ with decreasing $\mathrm{Si}_{3} \mathrm{~N}_{4}$ particle diameter. (a-

c) SEM cross-section view image of the $\mathrm{PU} / \mathrm{Si}_{3} \mathrm{~N}_{4}-\mathrm{CM}$ and magnified view of the center. The $\mathrm{Si}_{3} \mathrm{~N}_{4}$ particles with diameter of $0.96,0.71$ and $0.45 \mu \mathrm{m}$ were randomly embedded in the PU matrix at $\mathrm{Si}_{3} \mathrm{~N}_{4}$ loadings of $30 \mathrm{wt} . \%$. 

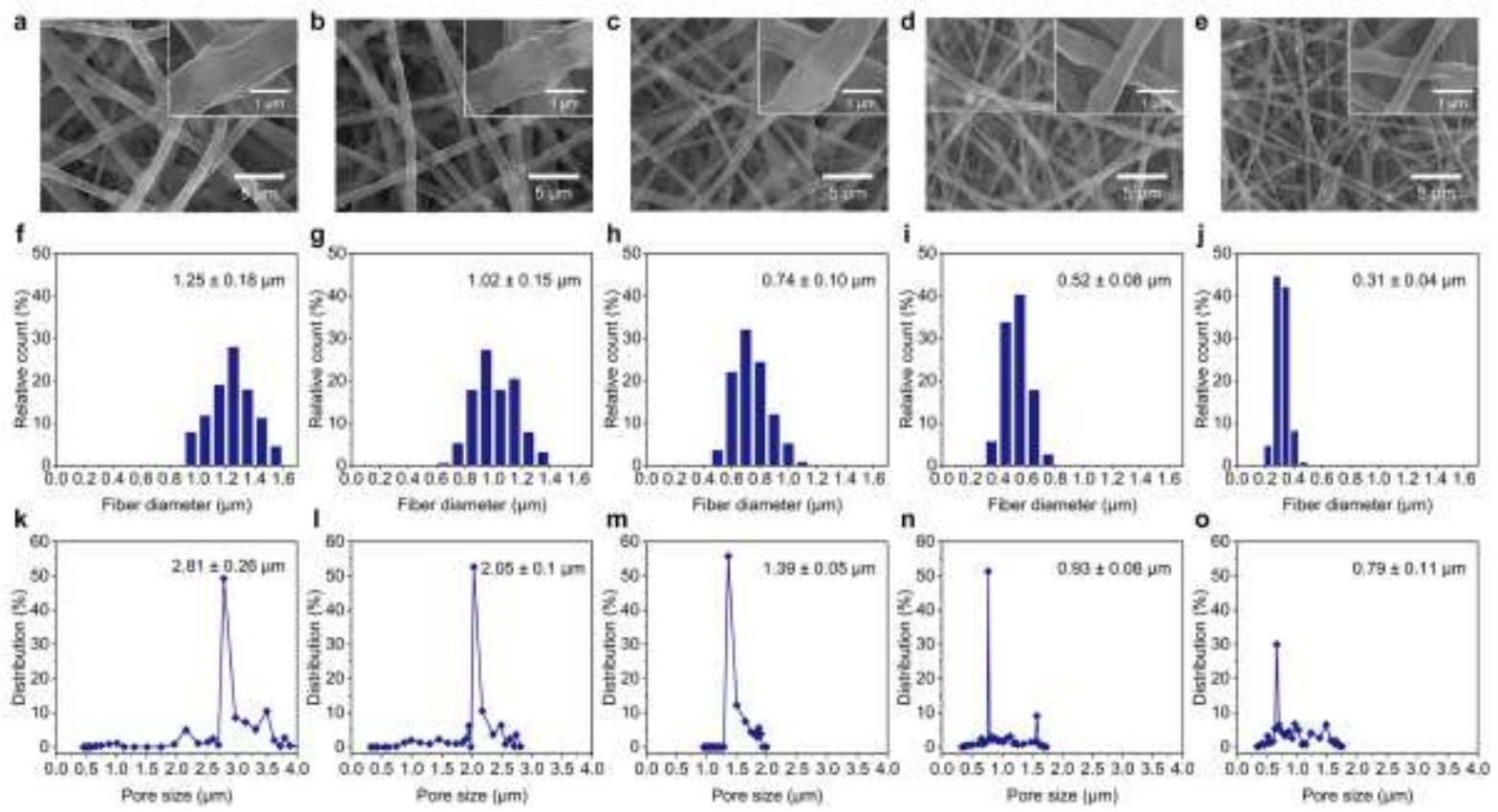

Figure S10. Typical morphology of the PU/Si3 $\mathrm{N}_{4}-\mathrm{FM}$. (a-e) SEM images of the $\mathrm{PU} / \mathrm{Si}_{3} \mathrm{~N}_{4}-\mathrm{FM}$ with decreasing fiber diameter of $1.25,1.02,0.74,0.52$ and $0.31 \mu \mathrm{m}$. (f-j) The corresponding fiber diameter distributions of the $\mathrm{PU} / \mathrm{Si}_{3} \mathrm{~N}_{4}-\mathrm{FM}$. (k-o) The corresponding pore size distribution of the $\mathrm{PU} / \mathrm{Si}_{3} \mathrm{~N}_{4}-\mathrm{FM}$.

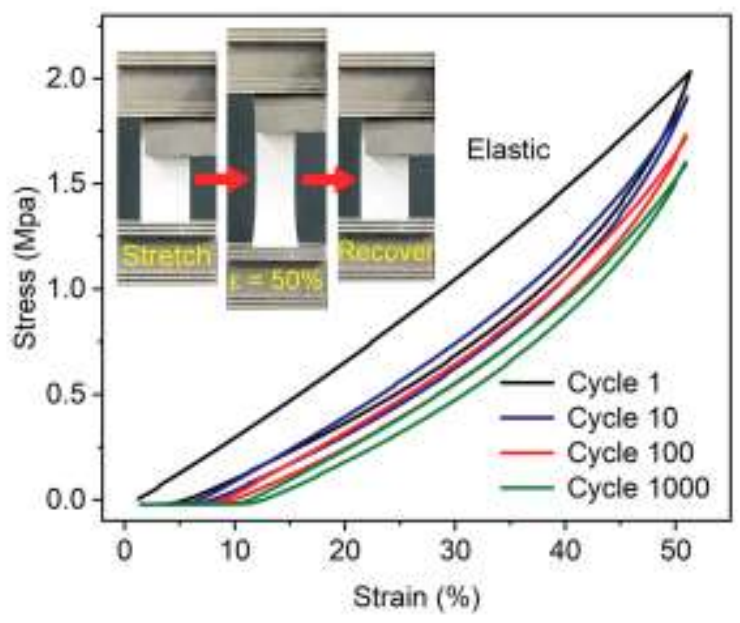

Figure S11. Cyclic tensions under 50\% strain of the PU/Si3 $\mathrm{N}_{4}-\mathrm{FM}$. 

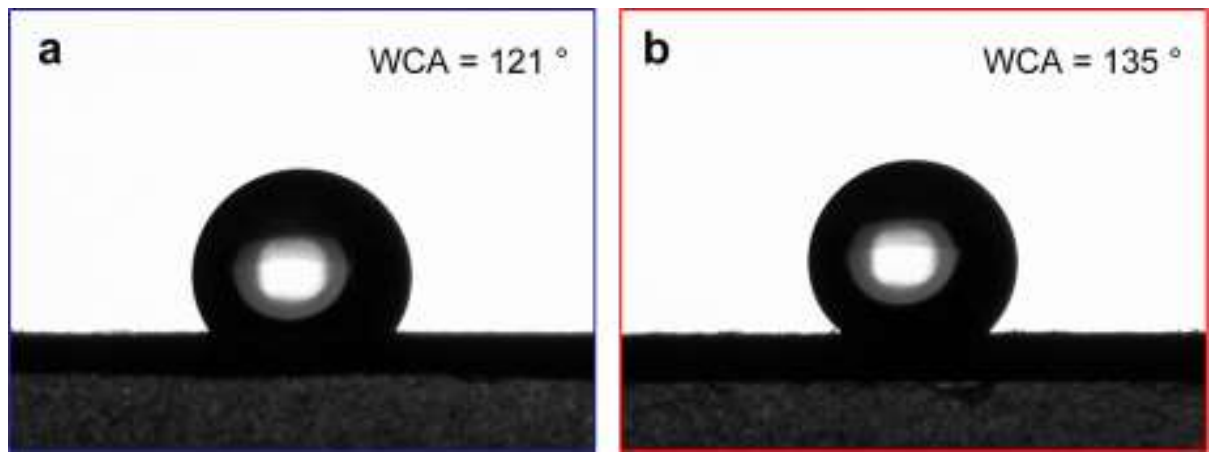

Figure S12. The water contact angles of (a) PU-FM and (b) $\mathrm{PU} / \mathrm{Si}_{3} \mathrm{~N}_{4}-\mathrm{FM}$ before air plasma treatment, indicating the enhanced hydrophobicity.
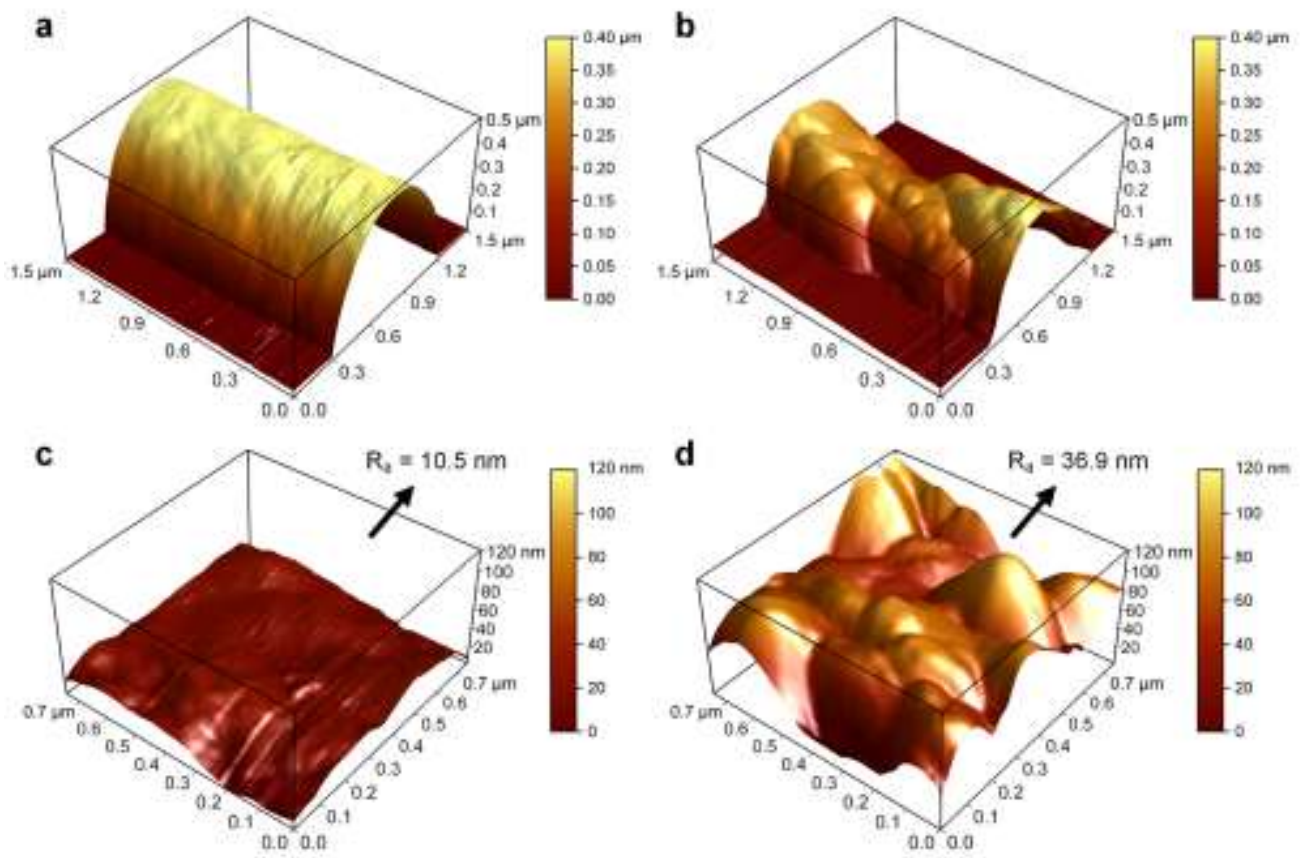

Figure S13. (a and b) AFM images of the original PU and PU/Si $\mathrm{N}_{4}$ fibers. (c and d) The images were further plane fitted to calculate the average roughness of the PU and $\mathrm{PU} / \mathrm{Si}_{3} \mathrm{~N}_{4}$ fiber surfaces. 


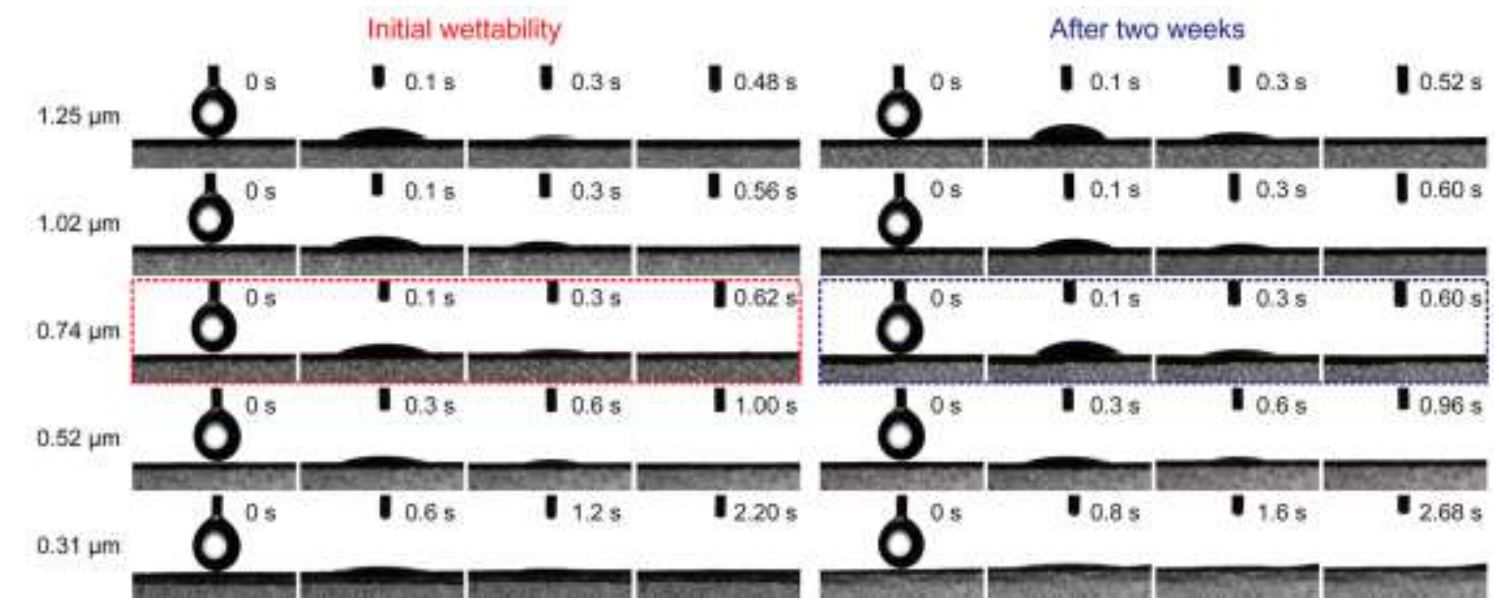

Figure S14. Stable wettability of the plasma-treated PU/Si3 $\mathrm{N}_{4}-\mathrm{FMs}$ (both top and bottom sides were treated for $10 \mathrm{~min}$ ). The water contact angle of plasma-treated $\mathrm{PU} / \mathrm{Si}_{3} \mathrm{~N}_{4}-\mathrm{FMs}$ before and after aging in room temperature for two weeks, showing the stable superhydrophilic fibrous substrate.

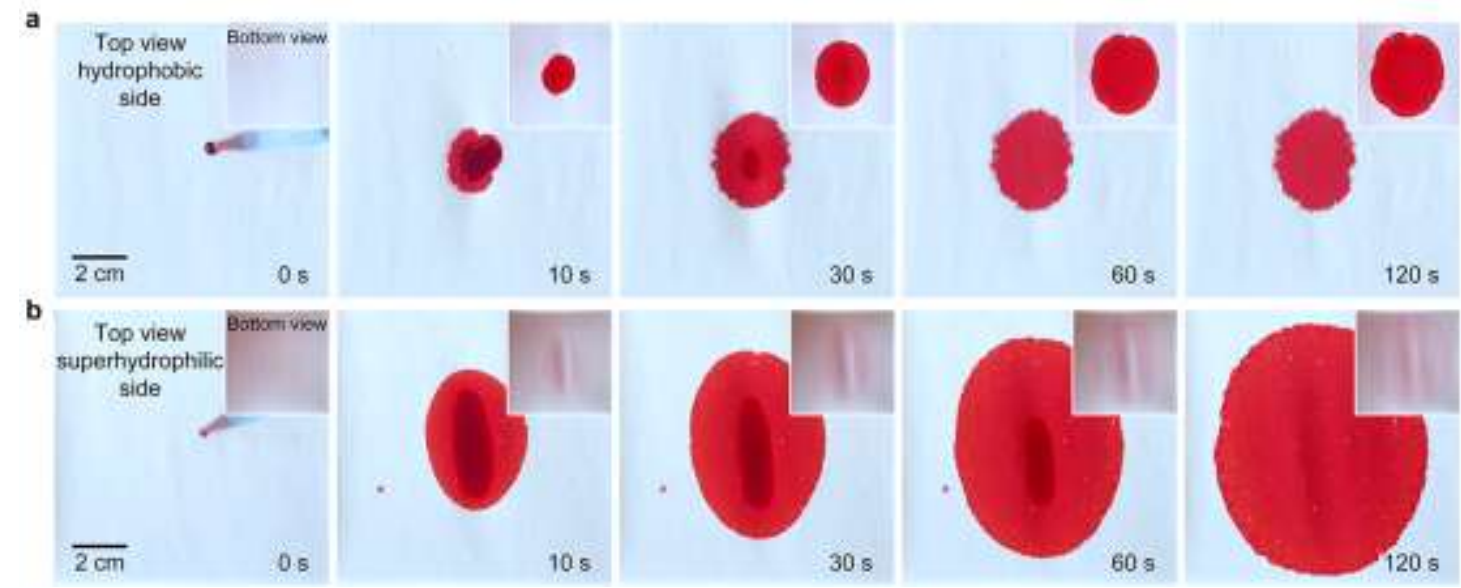

Figure S15. Top view and bottom view (inset images) of the directional water transportation through the plasma-treated PU/Si3 $\mathbf{N}_{4}$-FM. (a and b) Water droplets (ink droplets, $200 \mu \mathrm{L}$ ) were dropped on the hydrophobic side and superhydrophilic side, respectively. 


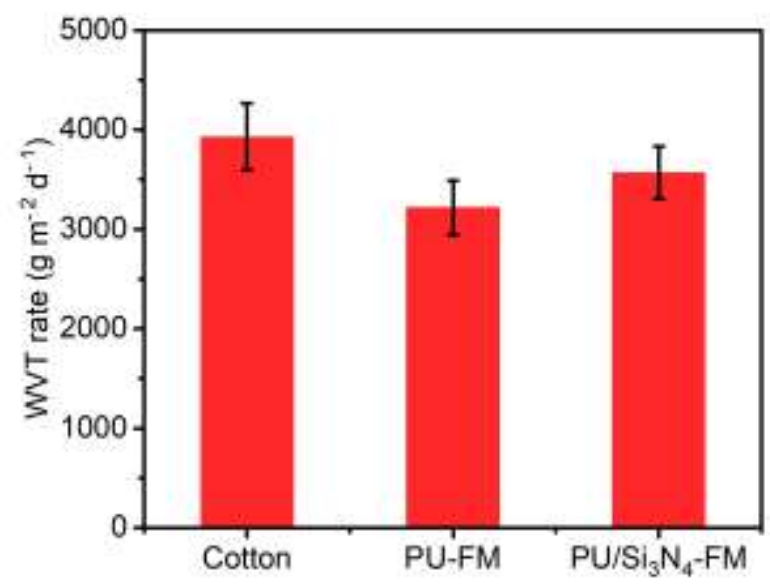

Figure S16. Water vapor transport (WVT) rate of the cotton, PU-FM, and PU/Si3 $\mathrm{N}_{4}-\mathrm{FM}$.

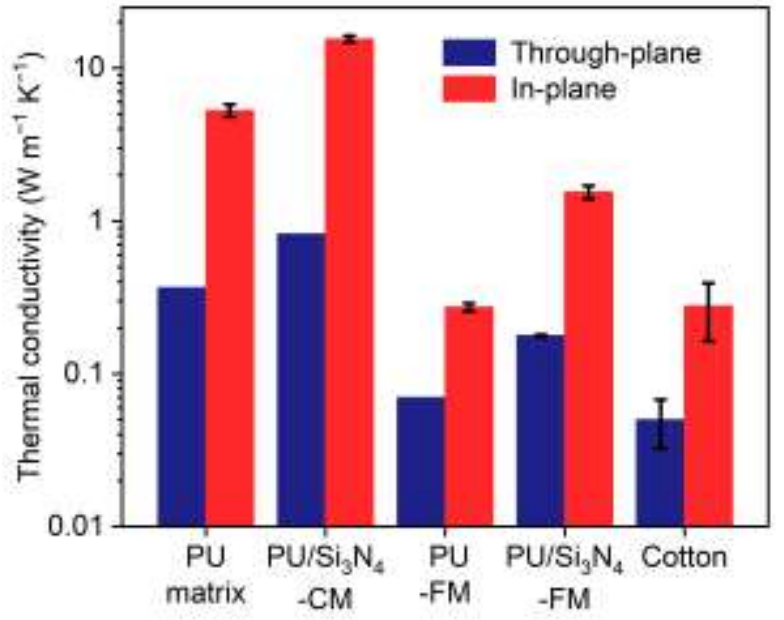

Figure S17. Through-plane and in-plane thermal conductivities of the cotton, solid and fibrous membranes at room temperature.

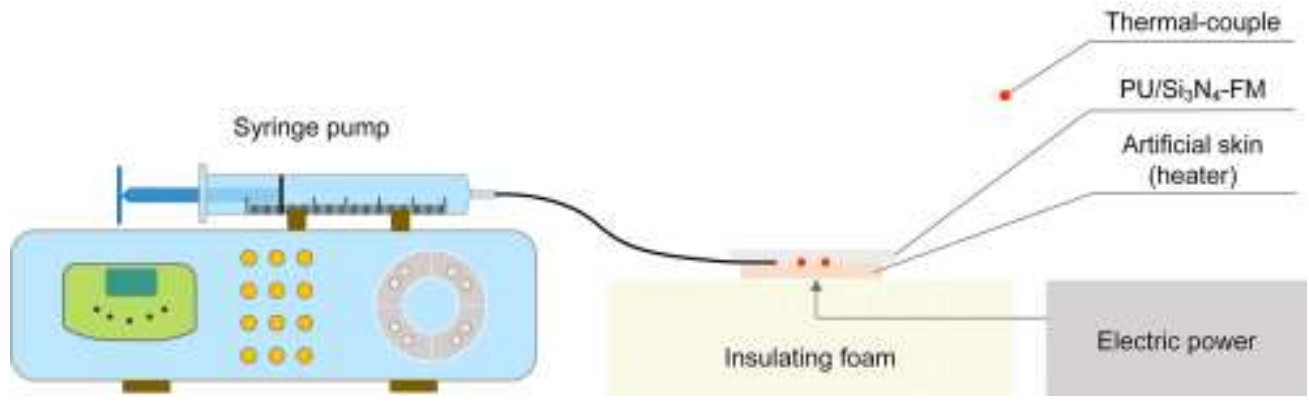

Figure S18. Schematic showing the sweat evaporation simulation setup. 
Table S1. A summary of the detailed sample information and thermal properties.

\begin{tabular}{cccccccc}
\hline Samples & $\begin{array}{c}P \\
(\%)\end{array}$ & $\begin{array}{c}\rho \\
\left(\mathrm{g} \mathrm{cm}^{-3}\right)\end{array}$ & $\begin{array}{c}C_{\mathrm{P}} \\
\left(\mathrm{J} \mathrm{g}^{-1} \mathrm{~K}^{-1}\right)\end{array}$ & $\begin{array}{c}\alpha \\
\text { Through-plane } \\
\left(\mathrm{mm}^{2} \mathrm{~s}^{-1}\right)\end{array}$ & $\begin{array}{c}\alpha \\
\text { In-plane } \\
\left(\mathrm{mm}^{2} \mathrm{~s}^{-1}\right)\end{array}$ & $\begin{array}{c}K \\
\text { Through-plane } \\
\left(\mathrm{mm}^{2} \mathrm{~s}^{-1}\right)\end{array}$ & $\begin{array}{c}K \\
\text { In-plane } \\
\left(\mathrm{W} \mathrm{m}^{-1} \mathrm{~K}^{-1}\right)\end{array}$ \\
\hline $\mathrm{PU}$ matrix & 0 & 1.120 & 1.902 & 0.172 & 2.490 & 0.366 & 5.304 \\
$\mathrm{PU} / \mathrm{Si}_{3} \mathrm{~N}_{4}-\mathrm{CM}$ & 0 & 1.390 & 1.687 & 0.351 & 6.621 & 0.823 & 15.530 \\
$\mathrm{PU}-\mathrm{FM}$ & 63.5 & 0.409 & 1.993 & 0.086 & 0.335 & 0.070 & 0.273 \\
$\mathrm{PU} / \mathrm{Si}_{3} \mathrm{~N}_{4}-\mathrm{FM}$ & 66.2 & 0.469 & 1.683 & 0.225 & 1.958 & 0.178 & 1.547 \\
$\mathrm{Cotton}$ & 79.4 & 0.326 & 1.689 & 0.091 & 0.506 & 0.050 & 0.278 \\
\hline
\end{tabular}

\section{Captions of Movies}

Movie S1. Cyclic tensions under $50 \%$ strain of the $\mathrm{PU} / \mathrm{Si}_{3} \mathrm{~N}_{4}-\mathrm{FM}$.

Movie S2a. Cross-sectional view of the directional water transportation through $\mathrm{PU} / \mathrm{Si}_{3} \mathrm{~N}_{4}-\mathrm{FM}$, the water was supplied upward to the hydrophobic side.

Movie S2b. Cross-sectional view of the directional water transportation through $\mathrm{PU} / \mathrm{Si}_{3} \mathrm{~N}_{4}-\mathrm{FM}$, the water was supplied upward to the superhydrophilic side.

Movie S3a. Top view of the directional water transportation through $\mathrm{PU} / \mathrm{Si}_{3} \mathrm{~N}_{4}-\mathrm{FM}$, the water was dropped on the hydrophobic side.

Movie S3b. Bottom view of the directional water transportation through $\mathrm{PU} / \mathrm{Si}_{3} \mathrm{~N}_{4}-\mathrm{FM}$, the water was dropped on the hydrophobic side.

Movie S3c. Top view of the directional water transportation through $\mathrm{PU} / \mathrm{Si}_{3} \mathrm{~N}_{4}-\mathrm{FM}$, the water was dropped on the superhydrophilic side.

Movie S3d. Bottom view of the directional water transportation through $\mathrm{PU} / \mathrm{Si}_{3} \mathrm{~N}_{4}-\mathrm{FM}$, the water was dropped on the superhydrophilic side. 


\section{Supplementary References}

(1) Zeyghami, M.; Goswami, D. Y.; Stefanakos, E. A review of clear sky radiative cooling developments and applications in renewable power systems and passive building cooling. Sol. Energ. Mat. Sol. C. 2018, 178, 115-128.

(2) ASTM International. ASTM G173-03 Standard Tables for Reference Solar Spectral Irradiances: Direct Normal and Hemispherical on $37^{\circ}$ Tilted Surface; West Conshohocken, PA, 2020.

(3) Mandal, J.; Fu, Y.; Overvig, A. C.; Jia, M.; Sun, K.; Shi, N. N.; Zhou, H.; Xiao, X.; Yu, N.; Yang, Y. Hierarchically porous polymer coatings for highly efficient passive daytime radiative cooling. Science 2018, 362, 315-319.

(4) Boyd, R. W. Radiometry and the Detection of Optical Radiation; John Wiley \& Sons: New York, 1983.

(5) Zeng, S.; Pian, S.; Su, M.; Wang, Z.; Wu, M.; Liu, X.; Chen, M.; Xiang, Y.; Wu, J.; Zhang, M.; Cen, Q.; Tang, Y.; Zhou, X.; Huang, Z.; Wang, R.; Tunuhe, A.; Sun, X.; Xia, Z.; Tian, M.; Chen, M.; Ma, X.; Yang, L.; Zhou, J.; Zhou, H.; Yang, Q.; Li, X.; Ma, Y.; Tao, G. Hierarchical-morphology metafabric for scalable passive daytime radiative cooling. Science 2021, 373, 692-696.

(6) Vogt, M. R. Development of physical models for the simulation of optical properties of solar cell modules. Leibniz University Hannover, Hannover, Germany, 2015. 